\title{
Granulocyte Macrophage Colony Stm Factor Measurement
}

National Cancer Institute

\section{Source}

National Cancer Institute. Granulocyte Macrophage Colony Stm Factor Measurement. NCI Thesaurus. Code C82019.

The determination of the amount of granulocyte macrophage colony stimulating factor present in a sample. 